\title{
A Longitudinal Investigation of the Role of Quantity and Quality of Child-Directed Speech in Vocabulary Development
}

\section{Citation}

Rowe, Meredith L. 2012. "A Longitudinal Investigation of the Role of Quantity and Quality of ChildDirected Speech in Vocabulary Development." Child Development 83 (5): 1762-1774.

\section{Published Version}

doi:10.1111/j.1467-8624.2012.01805.x

\section{Permanent link}

http://nrs.harvard.edu/urn-3:HUL.InstRepos:13041207

\section{Terms of Use}

This article was downloaded from Harvard University's DASH repository, and is made available under the terms and conditions applicable to Other Posted Material, as set forth at http:// nrs.harvard.edu/urn-3:HUL.InstRepos:dash.current.terms-of-use\#LAA

\section{Share Your Story}

The Harvard community has made this article openly available.

Please share how this access benefits you. Submit a story.

Accessibility 


\title{
A Longitudinal Investigation of the Role of Quantity and Quality of Child-Directed Speech in Vocabulary Development
}

\author{
Meredith L. Rowe \\ University of Maryland
}

\begin{abstract}
Quantity and quality of caregiver input was examined longitudinally in a sample of 50 parent-child dyads to determine which aspects of input contribute most to children's vocabulary skill across early development. Measures of input gleaned from parent-child interactions at child ages 18, 30, and 42 months were examined in relation to children's vocabulary skill on a standardized measure 1 year later (e.g., 30, 42, and 54 months). Results show that controlling for socioeconomic status, input quantity, and children's previous vocabulary skill; using a diverse and sophisticated vocabulary with toddlers; and using decontextualized language (e.g., narrative) with preschoolers explains additional variation in later vocabulary ability. The differential effects of various aspects of the communicative environment at several points in early vocabulary development are discussed.
\end{abstract}

One of the most powerful predictors of a child's ability to learn to read and succeed in school is vocabulary size at kindergarten entry (Anderson \& Freebody, 1981; Cunningham \& Stanovich, 1997; Duncan, Yeung, Brooks-Gunn, \& Smith, 1998; Durham, Farkas, Hammer, Tomblin, \& Catts, 2007; Farkas \& Beron, 2004; Snow, Burns, \& Griffin, 1998). From the earliest stages of language learning, children vary widely in their vocabulary size and rate of development (Fenson et al., 1994). Different theories of language acquisition emphasize different sources of this variation. An interactionist perspective to language learning stresses the importance of children's early environments and social interactions in the course of language acquisition (Braine, 1994; Snow, 1972, 1994). While it is acknowledged that some of this variability is likely due to genetics (see Stromswold, 2001, for a review), environmental factors also play an integral

This research was supported by grants from the National Institute of Child Health and Human Development: K99/R00HD055522 to the author, and P01HD40605 to Susan Goldin-Meadow. I thank the participating families for sharing their child's language development with us; Anthony Dick, Susan Goldin-Meadow, Janellen Huttenlocher, Daniel Kreisman, and Barbara Alexander Pan for comments on earlier versions of the article; Karyn Brasky, Laura Chang, Elaine Croft, Kristin Duboc, Jennifer Griffin, Sarah Gripshover, Kelsey Harden, Lauren King, Max Masich, Carrie Meanwell, Erica Mellum, Molly Nikolas, Jana Oberholtzer, Lilia Rissman, Becky Seibel, Meredith Simone, Calla Trofatter, Kevin Uttich, Julie Wallman, and Kristin Walters for help in collecting and transcribing the data; Christine Bascetta for coding; and Kristi Schonwald and Jason Voigt for administrative and technical assistance.

Correspondence concerning this article should be addressed to Meredith Rowe, Department of Human Development, 3304T Benjamin Building, University of Maryland, College Park, MD 20742. Electronic mail may be sent to mrowe@umd.edu. role (see Hoff, 2006, for a review). One important environmental factor that contributes to individual differences in early vocabulary development is the linguistic input to which children are exposed (Hart \& Risley, 1992, 1995; Hoff, 2003a, 2003b; Huttenlocher, Haight, Bryk, Seltzer, \& Lyons, 1991; Newport, Gleitman, \& Gleitman, 1977; Pan, Rowe, Singer, \& Snow, 2005).

While there is abundant evidence that parental communication with children relates to child vocabulary development, different studies focus on different measures of input, and it is often difficult to determine what the effects of various input measures would be if considered together. That is, some research suggests that the sheer amount of talk matters (Huttenlocher et al., 1991), while other research finds that specific types of speech (e.g., use of sophisticated vocabulary; Weizman \& Snow, 2001) and diversity of input (Huttenlocher, Waterfall, Vasilyeva, Vevea, \& Hedges, 2010) play an important role. Furthermore, studies vary in key background characteristics (e.g., the socioeconomic status [SES]) of the participants and the ages of the participating children. The present study addresses these issues by examining quantity and quality of parental communication with children across the early childhood period (18-42 months) in a sample diverse in SES. The goal is to go beyond the role of quantity and also simultaneously examine whether

(c) 2012 The Authors

Child Development (c) 2012 Society for Research in Child Development, Inc. All rights reserved. 0009-3920/2012/8305-0023

DOI: $10.1111 /$ j.1467-8624.2012.01805.x 
measures of input quality relate to vocabulary development at different child ages.

Much research on the role of parental communicative input in child vocabulary development emphasizes the importance of the quantity of input (i.e., the number of word tokens, or the total number of words, or utterances, spoken). In a study with middle-class families, Huttenlocher et al. (1991) found that amount of parental input predicts the rate of vocabulary growth between 14 and 26 months. Hart and Risley (1995) found even more striking results when they looked at variation in the quantity of input across the early childhood period in families ranging in SES. Extrapolations from their findings estimate that the average child from their higher SES, professional families was exposed to 215,000 words of language experience in a 100-h week, compared to 62,000 words for the average child in their low-SES families. By age 4, this translated to a difference of approximately 32 million words. In their study, Hart and Risley (1992, 1995) also found strong positive associations between quantity of caregiver input and children's vocabulary growth, supporting the notion that the quantity of parental vocabulary input influences children's rate of vocabulary growth. It is important to note, however, that Hart and Risley also found differences in the quality of caregiver input based on SES groups, with the parents from higher SES groups responding more to their children, producing more affirmatives and encouragements and fewer prohibitions with their children, and producing more diverse input in terms of the number of different nouns and modifiers produced per hour. Of course, quantity and quality measures are associated with one another (e.g., parents who talk more also produce more diverse talk; Hoff \& Naigles, 2002), yet it would be helpful to know the extent to which the relation between caregiver input and child vocabulary development is driven by the quantity of the talk, the quality of the talk, or both, and whether different aspects of caregiver input matter more at different points in child vocabulary development.

Research on the quality of parental talk suggests this might be the case, as some features of parental talk may relate more to child language development at different child ages than others. One basic measure of the quality of input is the diversity of parent vocabulary, often calculated as word types, or the number of different word roots produced. A longitudinal study with a large low-income sample found that parent word types were a better predictor of child vocabulary growth between 14 and 36 months (also measured in word types) than par- ent word tokens (Pan et al., 2005). Thus, the strong relation between parent types and parent tokens does not completely discount differences in the contribution of each factor to vocabulary growth. These results differ from the above-mentioned results found by Huttenlocher et al. (1991). However, vocabulary growth in the large low-income sample was measured over a longer period of development (14-36 months instead of 14-26 months). Therefore, it could be that diversity of vocabulary input plays more of a role in vocabulary growth when children get older, and sheer quantity plays a more important role when children are in the more initial stages of vocabulary acquisition. It is also possible that these two studies resulted in different findings because of differences in the samples. For example, the positive correlation between input quantity and vocabulary outcomes found in middle-class samples (Huttenlocher et al., 1991) may be more modest in low-income samples where the quality of talk might differ, on average, in other significant ways (Pan et al., 2005). For example, as noted above, studies find a number of average differences across SES groups in parental use of encouragements, directives, prohibitives, and elicitations (Farran \& Haskins, 1980; Hart \& Risley, 1995; Heath, 1983). This suggests that amount of input (quantity) and specific types of input (quality), although strongly related, may be confounded with SES. Thus, it is essential to look at the influence of quantity and quality of input on child vocabulary development in a longitudinal sample where SES (and early child language skill) can be controlled and where the effects of different measures of input can be examined simultaneously.

In a more recent study, Huttenlocher et al. (2010) conducted a sophisticated analysis of this sort looking at the role of quantity of input (e.g., word tokens) and diversity of input (i.e., variety of words and syntactic structures) in children's vocabulary and syntactic growth with a sample diverse in SES. They found that quantity and diversity of input related to SES. However, when quantity and diversity were included together in the same growth model, they were both nonsignificant, suggesting they were too highly related or collinear to use as simultaneous predictors. Furthermore, controlling for SES, diversity of caregiver speech was a significant predictor of within-person change in child vocabulary growth, measured as child word types produced between 26 and 46 months.

Both of the above-mentioned studies (e.g., Huttenlocher et al., 2010; Pan et al., 2005) relied on 
the children's production of word types during the parent-child interaction as a measure of vocabulary growth. Indeed, the study by Huttenlocher et al. (2010) found that children's vocabulary use had some effect on caregiver vocabulary use. Additional previous work also showing clear links between parent input and child vocabulary use has primarily relied on parent input measures and child vocabulary measures that are from the same, concurrent interactions (Hoff, 2003a, 2010). Thus, it is clear that there are strong relations between caregiver talk and child vocabulary used at that same time, or in corresponding interactions with the parent. In the present study, we add to this literature by looking at measures of caregiver input produced with children as predictors of children's vocabulary skill assessed by a researcher-administered standardized test. This allows us to examine the role of caregiver input in child vocabulary skill using a measure that is not contaminated by concurrent influences of caregiver speech. This approach will help determine the robustness of caregiver input effects on child vocabulary skill. Previous work has shown links between children's word types produced during interactions with parents and performance on standardized vocabulary measures (Pan, Rowe, Spier, \& Tamis-LeMonda, 2004). Thus, it is reasonable to assume that caregiver input will relate to vocabulary skill measured via standardized tests, yet the associations will likely not be as large as they would be with child vocabulary produced during the concurrent interaction.

Other measures of input quality are of interest in addition to vocabulary diversity: parents' vocabulary sophistication (e.g., rare words) and decontextualized language use. Studies show that preschoolers whose parents use a higher proportion of rare vocabulary have larger vocabularies in kindergarten and second grade (Beals, 1997; Beals \& Tabors, 1995; Weizman \& Snow, 2001). This is an especially striking finding, as rare words made up less than $2 \%$ of total word types used by the low-income parents studied. This result suggests that sophistication of vocabulary use is a powerful element of communicative input related to child vocabulary development (Weizman \& Snow, 2001) and may be an even more fine-grained predictor of child vocabulary skill than quantity (tokens) or diversity (types) of vocabulary.

Decontextualized language (Snow, 1990) is language that is removed from the here and now. Examples of decontextualized language use in early conversations between parents and children are seen in parents' use of explanations, narratives, pre- tend, nonimmediate talk during book reading, and formal definitions (e.g., Snow, Tabors, \& Dickinson, 2001). By exposing children to this type of challenging talk, parents can provide them with practice in the forms of discourse they must come to master in school. Thus, it is not surprising that research has found a link between parent and child uses of rare words and decontextualized language and children's later vocabulary and reading comprehension skills (e.g., Snow et al., 2001). For example, Katz (2001) found that mothers' use of pretend utterances during play with 3-year-olds was positively related to children's vocabulary comprehension and to their ability to provide formal definitions in kindergarten. Furthermore, Beals (2001) found concurrent relations between the percentage of explanatory parent talk or narrative talk during family mealtimes and children's vocabulary skills at age 5 . These findings suggest that using decontextualized talk with preschoolers engages them in challenging conversations that potentially increase vocabulary knowledge.

In summary, research to date on parental use of sophisticated vocabulary and decontextualized language has shown positive findings in relation to children's vocabulary skill, yet the work is scarce and limited to studies of low-income families and to parents talking to children age 3 or older. Furthermore, previous research has not examined whether sophisticated vocabulary use and decontextualized talk relate to child vocabulary when the quantity of input is controlled, or whether it is helpful to use sophisticated vocabulary or decontextualized talk with younger children. Thus, there is limited knowledge of the extent and consequences of these types of parental input across the early childhood period.

\section{The Present Study}

The goal of the present study is to examine parents' use of sophisticated vocabulary and decontextualized language with their children to determine whether these input quality measures explain children's subsequent vocabulary skill over and above the quantity of input to which children are exposed. To address this aim, quantity and quality measures of parental input were examined in the same 50 families at child ages 18, 30, and 42 months. Children's vocabulary comprehension was assessed by a researcher at ages 30, 42, and 54 months. Our approach was to use input quality measures from each visit (e.g., 18 months) to predict vocabulary skill at the next visit 1 year later 
(e.g., 30 months), controlling for prior child vocabulary skill, SES, and input quantity. The specific research questions are:

1. How much variation is there across families in the quantity and quality of parental talk to 18-, 30-, and 42-month-olds, and does this variation relate to SES?

2. Does variation in child vocabulary skill at 30 , 42 , and 54 months relate to quantity and quality of parent input (at the previous age)?

3. Controlling for SES, previous vocabulary skill, and quantity of input, do measures of input quality (vocabulary diversity and sophistication or decontextualized language) also explain variation in later vocabulary skill?

\section{Method}

Participants

Fifty children and their primary caregivers participated in the study. The parent-child dyads were drawn from a larger sample of 64 families participating in a longitudinal study of children's language development in the greater Chicago area. These families were recruited via direct mailings to roughly 5,000 families living in targeted zip codes and an advertisement in a free, monthly parent magazine. Interested parents were interviewed about background characteristics and a final sample of 64 families was selected to be representative of the greater Chicago area in terms of ethnicity and income. Exclusionary criteria for the current sample were the following: First, 8 of the 64 families were eliminated because both parents shared the primary care-giving role and their triadic interactions with the child during data collection were not considered comparable to the other dyadic interactions. Of the remaining 56 families, 1 was excluded because of a developmental diagnosis known to affect language development (i.e., autism spectrum disorder); 4 were excluded because they did not participate in all three visits at ages 18, 30, and 42 months; and 1 was excluded because the primary caregiver changed over time. Thus, the final sample for the present study includes 50 primary caregiver-child dyads. One of the primary caregivers is a father and the rest are mothers. The average education level of the primary caregivers is 15.8 years. Thirty-three of the children are White, 8 are Black, 4 are Hispanic, 3 are Asian, and 2 are of Mixed Race. In this sample, SES is confounded with race and thus it is unfortunately impossible to tease apart the two factors and consider race as a variable in analysis. Twenty-seven of the children are boys and 31 are first-borns. All parents speak English in the home as the primary language.

\section{Procedure and Transcription}

Parents were contacted by a researcher to schedule the home visits. In the larger study, visits occurred every 4 months between 14 and 54 months of age. Three sessions, 1 year apart, were chosen for this study $(18,30$, and 42 months) because of the extensive coding involved. Each research assistant on the project was assigned a certain number of families and stayed with those families over time. An initial home visit was conducted with the parents at or before child age 14 months to collect background information including parent education. At each home visit, the research assistant played with the child one-on-one in a free-play session, videotaped the parent-child interaction, and administered some tasks which differed depending on child age. The order of these activities often depended on the parents' preference or schedule. For the parent-child videotaped interaction, the dyads were videotaped engaging in their ordinary daily activities for $90 \mathrm{~min}$. As our goal was to get a representative picture of each child's typical home environment, we did not bring any toys with us and instead asked the families to do what they would typically do. Parents and children were not restricted to any room or space and were followed around by the research assistant with a handheld videocamera. Parents and children engaged in a variety of activities, but typical sessions included mostly playing and eating meals or snacks. At child age 30, 42, and 54 months the children were administered the Peabody Picture Vocabulary Test (PPVT-III; Dunn \& Dunn, 1997), a measure of vocabulary comprehension.

All caregiver speech to the child and child speech in the videotaped sessions were transcribed by the same research assistant who did the videotaping. The unit of transcription was the utterance, defined as any sequence of words that is preceded and followed by a pause, a change in conversational turn, or a change in intonational pattern. Occasionally, siblings or other family members were home during the interactions so only parent speech directed to the target child was transcribed. Transcription reliability was established by having a second individual transcribe $20 \%$ of each transcriber's videotapes with a reliability criterion that 
the two transcribers had to be in agreement on $95 \%$ of the utterances.

\section{Coding and Measures}

\section{Input Quantity}

Word tokens. The total number of words (word tokens) parents produced during the 90-min interaction served as the measure of input quantity.

\section{Input Quality}

Vocabulary diversity. The total number of different word types that parents produced during the 90min interaction.

Vocabulary sophistication. The total number of different rare words that parents produced during the 90-min interaction. Rare words were identified using the same method described by Beals and colleagues (Beals \& Tabors, 1995; Weizman \& Snow, 2001): We started by removing all nondictionary words from the corpus of spoken parent words. We then removed the most common words (and all their inflected forms) known by fourth graders as judged by teachers and compiled in the Dale-Chall word list (Chall \& Dale, 1995; Dale \& Chall, 1948). The remaining words in the parent input corpus were considered rare words.

Decontextualized utterances. All utterances were coded as to whether or not they were decontextualized. Decontextualized utterances fell into three categories: explanation, pretend, and narrative. Definitions and examples of these types of utterances are provided in Table 1. Reliability for decontextualized utterance coding was achieved by having two coders independently code the first seven transcripts. On these transcripts, percent agreement averaged $91.4 \%$ (range $=86 \%-98 \%$ ) with a mean Cohen's kappa value of 0.82 (range $=0.76-0.87$ ). One of the coders then coded the remaining 43 transcripts. A second reliability check conducted on an additional transcript later in the process yielded comparable reliability (percent agreement $86 \%$; $\kappa=$ 0.76). Total raw numbers of utterances that were either explanations, pretend, or narrative were tallied and used in analyses.

\section{Socioeconomic Status}

Primary caregiver education (in years) was used as a measure of SES. The education level of the parents was collected categorically and subsequently assigned a value equivalent to years of education (less than high school $=10$ years, high school $=$ 12 years, some college or an associate degree $=$ 14 years, college degree $=16$ years, more than college $=18$ years). Primary caregivers averaged 15.8 years of education $(S D=2.1)$ with a range from 10 to 18 years.

\section{Child Vocabulary Skill}

Children were given the PPVT at child ages 30, 42 , and 54 months. Raw scores were converted to age-appropriate standardized scores based on the published norms. This nonverbal measure of receptive vocabulary was chosen as the vocabulary outcome measure of choice because the PPVT is a widely used measure of vocabulary skill and, importantly, because it provides data that are independent from the parent-child interaction.

\section{Other Potential Controls}

Child gender and birth order (first- or later-born) were considered in analyses but were dropped because they did not relate to child vocabulary skill at any of the three time points and were not significant when included in regression models. Thus, gender and birth order are not considered further here.

\section{Results \\ Descriptive Statistics}

Descriptive statistics for all communicative input measures at each child age are displayed in Table 2. Parents varied widely in the quantity and quality of their child-directed speech. For example, at child age 18 months, the number of word tokens parents produced during the 90-min interaction ranged from 360 to over 9,200. Similarly, at child age 30 months, some parents did not produce any narrative utterances, whereas others produced over 250 . It is also evident from Table 2 that the quantity measure (word tokens) does not increase steadily on average with child age, yet the quality measures do.

Because quantity of talk did vary at each time, we calculated proportions to describe the relative change over time in use of rare words and decontextualized language. The proportion of words used that were rare (rare words/word types) and the proportion of total utterances that were decontextualized (all decontextualized utterances/total utterances) increased over time as displayed in Figure 1. Linear contrasts (Furr, 2008; Rosenthal, 
Table 1

Definition and Examples of Categories of Decontextualized Utterances

\begin{tabular}{|c|c|c|}
\hline Category & Definition & Examples \\
\hline Explanations & $\begin{array}{l}\text { Talk that requested or made logical connection between } \\
\text { objects, events, concepts or conclusions (Beals, 1997, 2001) }\end{array}$ & $\begin{array}{l}\text { "Oh, we can't put them in the bus because the bus is } \\
\text { full of blocks." } \\
\text { "Because the lights have to be on for the remote to } \\
\text { work." }\end{array}$ \\
\hline Pretend & $\begin{array}{l}\text { Talk during pretend episodes of interaction including } \\
\text { making an object represent another; attributing actions, } \\
\text { thoughts, or feelings to inanimate objects; assuming a role } \\
\text { or persona, enacting scripts or routines (Katz, 2001) }\end{array}$ & $\begin{array}{l}\text { "I'll save you from the wicked sister." } \\
\text { "We have to have the police come and make an accident } \\
\text { report now." }\end{array}$ \\
\hline Narrative & $\begin{array}{l}\text { Talk about events that happened in the past or will happen } \\
\text { in the future (Beals \& DeTemple, 1993; Beals \& Snow, } \\
\text { 1994) }\end{array}$ & $\begin{array}{l}\text { "He is going to look in your nose and your throat and } \\
\text { your ears." } \\
\text { "Oh yes, we have popcorn in the movie theater, } \\
\text { remember?" }\end{array}$ \\
\hline
\end{tabular}

Table 2

Descriptive Statistics for Quantity and Quality Measures for Parent Input During 90-Min Interactions at Three Child Ages ( $\mathrm{n}=50)$

\begin{tabular}{lccc}
\hline & 18 months & 30 months & 42 months \\
& $M(S D)$ & $M(S D)$ & $M(S D)$ \\
& Range & Range & Range \\
\hline Input quantity & & & \\
Word tokens & $3,523(1,951)$ & $3,700(1,852)$ & $3,572(1,858)$ \\
& $360-9,227$ & $696-7,673$ & $488-9,528$ \\
Input quality & & & \\
Word types & $397(137)$ & $432(126)$ & $443(141)$ \\
& $95-714$ & $172-714$ & $144-841$ \\
Rare word types & $25(17)$ & $31(17)$ & $37(20)$ \\
& $1-83$ & $4-76$ & $6-100$ \\
Narrative utterances & $6.4(11.2)$ & $23.7(41.1)$ & $30.3(42.2)$ \\
& $0-85$ & $0-258$ & $0-220$ \\
Pretend utterances & $8.0(17.5)$ & $32.9(54.8)$ & $49.7(113.9)$ \\
& $0-85$ & $0-264$ & $0-637$ \\
Explanation utterances & $10.0(8.9)$ & $12.7(10.2)$ & $13.3(10.0)$ \\
& $0-46$ & $0-39$ & $0-45$ \\
\hline
\end{tabular}

Rosnow, \& Rubin, 2000) revealed a significant linear increase in the proportion of word types that were rare, $t(49)=5.36, p<.001$, and the proportion of utterances that were decontextualized, $t(49)$ $=5.63, p<.001$, from 18 to 42 months. For example, at 18 months, an average of only $2.2 \%(S D=1.8)$ of parent utterances were decontextualized utterances (narrative, pretend, or explanations) whereas by 42 months, the average percentage increased to 9.4\% (SD =9.2). Thus, as children get older and increase in language ability, parents devote more of their words to rare words, and more of their utterances to decontextualized talk. For all of the remaining analyses, we use raw input measures (e.g., number of word tokens) rather than proportions.

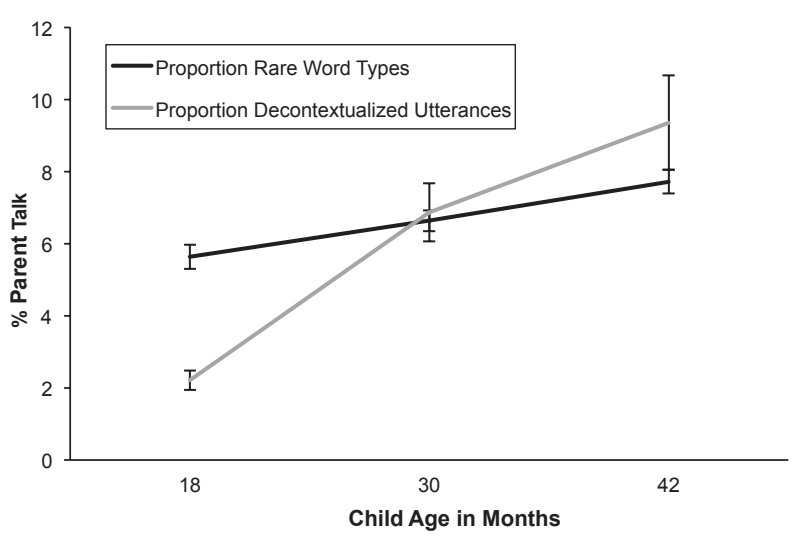

Figure 1. Change over time in proportion of vocabulary that is sophisticated and in proportion of utterances that are decontextualzed $(n=50)$.

Child PPVT scores varied widely at each age. At child age 30 months, the mean normed score was $96.2(S D=15.2)$, compared to $106.2(S D=17.4)$ at 42 months and $110.4(S D=18.2)$ at 54 months. PPVT scores at each age were positively related to one another $(r \mathrm{~s}=.65-.84, p<.001)$. At child ages 30 and 54 months, 2 children did not complete the PPVT and the sample size is 48 for each of those ages. At child age 42 months, all 50 children completed the PPVT.

\section{The Role of Parent Education}

Primary caregiver education is positively related to both quantity and quality measures as shown in Table 3. On average, more highly educated parents use more word tokens and use more diverse vocabulary (word types) at each child age than parents 
Table 3

Simple Correlations (Pearson's r) Between Parent Education and Quantity and Quality Measures at Three Child Ages ( $\mathrm{n}=50)$

\begin{tabular}{lccc}
\hline & \multicolumn{3}{c}{ Parent education } \\
\cline { 2 - 4 } & 18 months & 30 months & 42 months \\
\hline Input quantity & & & \\
$\quad$ Word tokens & $.41^{* *}$ & $.39^{* *}$ & $.36^{*}$ \\
Input quality & & & \\
$\quad$ Word types & $.39^{* *}$ & $.41^{* *}$ & $.36^{*}$ \\
$\quad$ Rare word types & $.24^{\dagger}$ & $.41^{* *}$ & $.30^{*}$ \\
Narrative utterances & .06 & .08 & .11 \\
Pretend utterances & $.31^{*}$ & $.36^{* *}$ & .10 \\
$\quad$ Explanation utterances & $.24^{\dagger}$ & .06 & $.32^{*}$ \\
\hline${ }^{\dagger} p<.10 .{ }^{*} p<.05 .{ }^{* *} p<.01$. & & &
\end{tabular}

with fewer years of education. Education is also positively related to rare word use, particularly at the later two ages, and to decontextualized utterances. Yet, the relation between parent education and decontextualized utterances is less consistent over time than that between education and quantity or vocabulary diversity and sophistication measures. For decontextualized utterances, both pretend utterances and explanations relate to parent education at one or more of the three child ages. Interestingly, narrative utterances are not significantly related to parent education at any child age (Table 3).

Parent education also relates to children's PPVT scores at all three ages $(r s=.40-.69, p<.01)$. In sum, as with previous studies (e.g., Hart \& Risley, 1995; Hoff, 2003b; Huttenlocher et al., 2010; Rowe, Pan, \& Ayoub, 2005) we find relations between caregiver education and input quantity and quality. And, not surprisingly, we find relations between caregiver education and children's scores on the PPVT. In the following analyses, after presenting uncontrolled relations between input characteristics and PPVT scores, we then also control for caregiver education when examining effects of input on child vocabulary skill. We know from previous research that parent input tends to mediate the effect of SES on child language abilities (Hoff, 2003a; Huttenlocher et al., 2010). Therefore, we expect that input measures and parent education will explain some of the same variation in PPVT scores. Subsequently, we expect that in multiple regression models, parameter estimates for parent education will decrease when input measures are included in the models. However, the goals of this study are not to test mediation effects but to examine the role of input measures with SES controlled to determine the most influential aspects of input on child language skill with all else being equal.

\section{Relations Between Input Measures and Child Vocabulary Skill}

To determine the role of input measures in child vocabulary skill, the following analytical approach was adopted. First, we considered the children's receptive vocabulary skills as measured on the PPVT at ages 30, 42, and 54 months as the outcome vocabulary measures of interest. By using standardized measures of child vocabulary, we can determine whether parent input relates to subsequent child vocabulary skill even when vocabulary is measured outside of the parent-child interaction. We first examined the zero-order correlations between input measures and PPVT scores. We then adopted a more developmental approach in that when predicting vocabulary skill at each age, we controlled for the child's vocabulary ability at the previous age. Thus, when predicting PPVT scores at 54 months, PPVT scores at 42 months are controlled and only input measures at 42 months are examined; when predicting PPVT scores at 42 months, PPVT scores at 30 months are controlled and only input measures at 30 months are examined; when predicting PPVT scores at 30 months, the first time the measure was given, input measures at 18 months are examined and we control for children's spoken word types during a parent-child interaction that took place at age 14 months. This general approach allows us to determine whether input measures explain additional variation in later vocabulary with earlier vocabulary controlled, and it therefore speaks to the specific role of input measures at different points in development. Furthermore, this is a conservative approach because children's earlier vocabulary skill was likely affected by earlier input in their environment. As a result, our input effects may be underestimated because they control for this earlier skill as well as caregiver education.

We began with zero-order correlations between input measures at each point in time and the PPVT at the following time. These associations are presented in Table 4 and show consistent significant positive relations between PPVT scores and input quantity (e.g., number of word tokens) and vocabulary diversity (e.g., number of word types). PPVT scores at the latter two ages relate to vocabulary sophistication (e.g., number of rare words) used at the prior visit. Furthermore, the number of 
Table 4

Zero-Order Correlations Between Children's Peabody Picture Vocabulary Test (PPVT) Scores at 30, 42, and 54 months and Parent Input Quantity and Quality Measures at the Preceding Time

\begin{tabular}{lccc}
\hline & \multicolumn{3}{c}{ PPVT } \\
\cline { 2 - 4 } & $\begin{array}{c}30 \text { months } \\
(n=48)\end{array}$ & $\begin{array}{c}42 \text { months } \\
(n=50)\end{array}$ & $\begin{array}{c}54 \text { months } \\
(n=48)\end{array}$ \\
\hline Word tokens & $.33^{*}$ & $.42^{* *}$ & $.37^{* *}$ \\
Word types & $.36^{*}$ & $.57^{* * *}$ & $.50^{* * *}$ \\
Rare word types & .24 & $.57^{* * *}$ & $.49^{* * *}$ \\
Narrative utterances & .19 & .21 & $.42^{* *}$ \\
Pretend utterances & .22 & .21 & .15 \\
Explanation utterances & $.29^{*}$ & .17 & $.36^{*}$ \\
\hline
\end{tabular}

${ }^{*} p<.05 .{ }^{* *} p<.01 .{ }^{* * *} p<.001$.

narrative utterances and explanations are significantly related to PPVT at the final age. The next step was to partial out our important controls and examine similar correlations to determine whether any of the quality measures continue to relate to PPVT scores with quantity of input, parent education, and earlier child vocabulary controlled. Thus, as with the zero-order correlations, we examined associations between each of the three PPVT outcome measures and the different parent input quality measures used during the previous interaction, controlling for parent education, the earlier measure of child vocabulary, and quantity of parent input measured as word tokens. The partial correlations are presented in Table 5 and are summarized next.

There were no significant relations between PPVT scores at 30 months and parent input quality measures at 18 months, controlling for quantity of parent input, parent education, and child word types spoken at 14 months of age. PPVT scores at 42 months were significantly related to parent word types at 30 months $(r=.43, p<.01)$ and to parent rare word types at 30 months $(r=.35, p<.05)$, controlling for parent word tokens, parent education, and child PPVT scores at 30 months. PPVT scores at 54 months were significantly related to parent use of explanations $(r=.29, p=.50)$ and narratives $(r=.34, p<.05)$ with parent word tokens, parent education, and child PPVT scores at 42 months controlled.

These partial correlations were followed up with multiple regression analyses to determine the simultaneous effects of controls and multiple input measures on subsequent vocabulary skill. The results of these multiple regression analyses predicting PPVT scores at each age are presented in
Table 5

Partial Correlations Between Children's Peabody Picture Vocabulary Test (PPVT) Scores at 30, 42, and 54 months and Parent Input Quality Measures (at the Preceding Time), Controlling for Parent Education, Previous Child Vocabulary Skill, and Parent Input Quantity (Word Tokens)

\begin{tabular}{lccc}
\hline & \multicolumn{3}{c}{ PPVT } \\
\cline { 2 - 4 } & $\begin{array}{c}30 \text { months } \\
(n=48)\end{array}$ & $\begin{array}{c}42 \text { months } \\
(n=50)\end{array}$ & $\begin{array}{c}54 \text { months } \\
(n=48)\end{array}$ \\
\hline Word types & 0.06 & $0.43^{* *}$ & -0.03 \\
Rare word types & -0.00 & $0.35^{*}$ & -0.11 \\
Narrative utterances & 0.02 & 0.02 & $0.34^{*}$ \\
Pretend utterances & 0.01 & 0.02 & -0.01 \\
Explanation utterances & 0.09 & -0.02 & $0.29^{*}$ \\
\hline
\end{tabular}

Note. The partial correlations with PPVT at 30 months control for parent education, child vocabulary production at 14 months, and parent word tokens at 18 months. The partial correlations with PPVT at 42 months control for parent education, PPVT scores at 30 months, and parent word tokens at 30 months. The partial correlations with PPVT at 54 months control for parent education, PPVT scores at 42 months, and parent word tokens at 42 months.

${ }^{*} p<.05 .{ }^{* *} p<.01$

Table 6. For each PPVT outcome measure, we first present the control model showing the effect of parent education and previous child vocabulary skill. Next we present a model that shows the effect of quantity of input with controls. Finally, we present models including input quality measures, focusing on those measures that proved significant in the partial correlation analysis. Thus, we use the correlations in Table 5 to guide our regression model building.

Model 1 in Table 6 shows the control model predicting PPVT scores at 30 months. Here, both parent education $(p<.01)$ and earlier child vocabulary $(p<.01)$ are significant positive predictors and combine to explain approximately $29 \%$ of the variation in PPVT scores at 30 months. When parent tokens was added as a predictor with the controls (Model 2), it was a marginally significant positive predictor of PPVT scores at 30 months $(p<.10)$, and the $R^{2}$ statistic increased by $5 \%$. As noted in the partial correlations, none of the measures of input quality were significant predictors after education, prior vocabulary skill, and input quantity were controlled. However, a separate model (not shown) indicated that if word types were used as a predictor instead of word tokens, word types is also a marginally significant predictor $(p<.10)$ with a slightly smaller $R^{2}$ statistic than in the model with word tokens. Thus, Model 2 in Table 5 is the best model we could fit using parent education, 
previous child language ability, and parent input measures at 18 months to predict child receptive vocabulary at 30 months. This model indicates that in addition to prior vocabulary skill and parent education, the quantity of parent input at 18 months is a positive predictor of child vocabulary at 30 months.

Models 3 through 6 in Table 6 show the results of the multiple regression analyses predicting PPVT scores at 42 months. Model 3 indicates that both parent education $(p<.05)$ and PPVT scores at 30 months $(p<.001)$ combine to explain approximately $52 \%$ of the variation in PPVT scores at 42 months. When parent tokens was added to the controls (Model 4) it was not a significant predictor, and there was no change in the $R^{2}$ statistic from the previous model. Thus, there is no effect of input quantity once controls are in the model. In Model 5, when parent word types were included, it was a significant positive predictor $(p<.01)$ and the $R^{2}$ from Model 4 increased by $9 \%$. Similarly, in Model 6 when the number of rare word types was included as a predictor instead of total word types, it was a significant positive predictor $(p<.01)$ and the resulting model showed an $R^{2}$ of $58 \%$, about $6 \%$ higher than nested Model 4. An additional model, not shown, revealed that word types and rare word types were too collinear to include in a model simultaneously. In sum, parents who use a wider range of vocabulary words or who use more sophisticated vocabulary with their 21/2-year-olds have children with higher PPVT scores 1 year later, as compared to parents who use less diverse or sophisticated vocabulary, controlling for children's vocabulary knowledge at the time of that interaction, parent education, and amount of parent talk.

Models 7 through 9 in Table 6 show the results of the regression models predicting PPVT scores at 54 months. Model 7 shows that parent education and children's PPVT scores at 42 months combine to explain over $72 \%$ of the variation in children's PPVT scores at 54 months. Model 8 includes parent tokens, which was a marginally significant predictor $(p<.06)$, and this model explains an additional $2 \%$ of the variation in PPVT scores at 54 months compared to Model 7. Model 9 shows that parent uses of decontextualized language at 42 months, particularly use of narrative utterances $(p<.05)$ and explanations $(p<.10)$ are positive predictors of child vocabulary, controlling for quantity of parent talk, parent education, and children's PPVT scores 1 year earlier. This model explains $79 \%$ of the variation in PPVT scores at 54 months. In sum, parents who use more decontextualized language with 
their $3^{1 / 2}$-year-olds have children with greater vocabulary skills 1 year later, compared to parents who use less decontextualized language, controlling for children's vocabulary skill at the time of that interaction, parent education, and quantity of parent talk.

\section{Discussion}

The present study shows that specific measures of input quality relate to child vocabulary skill at different points in development, even with SES and quantity of input controlled. This is an important finding because it indicates that: (a) the quantity of input is not the whole story and (b) the more finegrained aspects of input that do matter are dependent on the child's age or language ability. The results are consistent with a developmental scenario in which quantity of input is most important during the 2nd year of life, the diversity or sophistication of the vocabulary in the input is most important during the 3rd year of life, and the use of decontextualized language such as narrative and explanations in the input is most beneficial during the 4th year of life. Furthermore, in the present study we found that aspects of parent input relate to children's receptive vocabulary skills measured on a standardized test (e.g., PPVT). These results are important because they imply that differences in input reflect language knowledge in addition to language use (Hoff, 2003a). We discuss the results regarding the different aspects of input investigated here, keeping in mind that not all features of input quality were examined and that additional work is needed in this area.

At child age 18 months, quantity of parent input was most related to subsequent vocabulary skill with SES and previous vocabulary ability controlled, and none of the other input measures considered here explained additional variation in later vocabulary with input quantity controlled. This effect of input quantity is not surprising, as $1 \frac{1 / 2}{2}$ year-olds are in the early stages of vocabulary acquisition, and more input is likely better as it provides increased and multiple exposures to a variety of words. However, this does not mean that there are not other input quality measures that would be important at this age. For example, specific aspects of the interactive situation, such as episodes of joint attention (Tomasello \& Farrar, 1986) or uses of gesture to highlight the meanings of different words (Rowe \& Goldin-Meadow, 2009) might be more suitable quality measures for the earlier stages of language development than measures of vocabulary sophistication and decontextualized language. Thus, future work should be sensitive to the age of the child, and to the child's language ability, when investigating aspects of input that might relate to language development.

At child age 30 months, input rich in vocabulary diversity and sophistication was most related to vocabulary skill 1 year later even with input quantity controlled. One reason that vocabulary diversity and sophistication might be more useful than overall quantity of input at this age is that children aged 30 months have had more exposure to commonly used words, have built up a vocabulary base to draw upon, and are ready to pick up more difficult and sophisticated vocabulary from the talk to which they are exposed. In their previous studies on this topic, Beals (1997) and Weizman and Snow (2001) also found relations between vocabulary sophistication in the input and later child vocabulary skill. There are two differences worth mentioning between those previous studies and the current study. The first is that in the prior studies (Beals, 1997; Weizman \& Snow, 2001) researchers used density measures, or the proportion of total talk that was rare, as a predictor of child skill without explicitly controlling for the amount of input. The current study adds to that work by showing that with the quantity of talk controlled, the sheer number of different words, or the number of different rare words still explains variation in later child vocabulary skill. Furthermore, the previous studies were conducted with a completely low-income sample and found that $1.77 \%$ of parents' word types were sophisticated or rare words (Weizman \& Snow, 2001). In the current sample, when we created proportions we saw that approximately $6 \%$ of parents' word types were sophisticated word types and parents increased over time in their use of rare words. Perhaps differences in the samples in terms of SES might account for these average differences in rare word use, as the sample in the current study spanned a wider range of SES. Nonetheless, despite the relatively small proportion of talk that contains sophisticated vocabulary at child age 30 months, the vocabulary diversity and sophistication in the input matters. This finding also supports the recent finding by Huttenlocher et al. (2010) that vocabulary diversity in the input is a strong predictor of child vocabulary growth when measured in word types produced. In sum, we found that controlling for parent education, previous child vocabulary skill, and input quantity, parents who used more differ- 
ent words or rare words during interactions with their 30-month-olds had children with larger vocabularies 1 year later than parents who used fewer different or rare words.

At child age 42 months, parent use of decontextualized language, specifically use of narrative utterances, was related to later vocabulary skill, with quantity of talk, SES, and previous child vocabulary skill controlled. Thus, parents who talked more with their children about events that happened in the past or will happen in the future had children with larger vocabularies 1 year later than parents who produced fewer narrative utterances. This finding is comparable to previous work within a low-income sample showing a link between parental narrative utterances during mealtimes with 5-year-olds and children's vocabulary skill (Beals, 2001), and it extends the role of parent narrative even earlier to age $3 \frac{1}{2}$. One possible explanation for this finding is that parents who produce more narrative utterances are likely doing so because they are able to keep their child engaged in the conversation and are thus able to continue the topic longer. This could be due to child effects or to parental narrative style. Children who are more engaged in the interaction and more attentive and focused will find it easier to stay on topic; thus, parental use of narratives may be driven by child characteristics such as attention.

With respect to parental narrative style, previous research has documented individual differences in parents' abilities to elicit narratives from children (Fivush \& Fromhoff, 1988; Haden, Haine, \& Fivush, 1997; McCabe \& Peterson, 1991; Peterson \& McCabe, 1994; Snow \& Dickinson, 1990) and shows that in general, parental narrative behavior predates and correlates with children's narrative performance (Peterson \& McCabe, 1994). Thus, by exposing children to narrative discourse, parents can provide their children with experience engaging in conversations about topics removed from the here and now and scaffold their children's ability to produce narrative discourse themselves (Bruner, 1983; Vygotsky, 1978). This is a difficult task that draws heavily on children's knowledge of vocabulary. Thus, parental narratives likely relate to later child vocabulary skill both because they provide the child with experience with the challenging task of comprehending decontextualized language and because they encourage children to practice producing their own narrative utterances.

It is also worth noting that parental use of narratives in this study was not related to parental educa- tion. This is interesting in its own right, as all of the other input measures were related to SES. Statistically, this could mean that one reason parental narrative use remained important in the models is that it explains additional variation in PPVT scores not already explained by SES, prior vocabulary skill, and quantity of talk. More substantively, it suggests that narrative utterances are positively related to child vocabulary outcomes at this age and that it is not necessarily the higher SES parents who are producing more narratives. Parents may talk about the future or the past during day-to-day interactions for various reasons. One reason could be the context of the interaction, as we know that some contexts may elicit more decontextualized narrative talk than others. For example, book reading is found to elicit talk about the nonpresent (DeTemple, 2001). In the current study, we initially coded nonimmediate talk during book reading as a separate measure of decontextualized language, yet it occurred so infrequently overall that we ultimately added those uses of nonimmediate talk to the narrative measure. We found that the narrative findings held whether or not they included the bookreading utterances, suggesting that the role of narrative talk in later vocabulary skill is not driven by narrative talk during book reading interactions. Another reason parents may talk more or less about the nonpresent could be due to their cultural communicative styles. We know from Heath's (1983) work that some parents value storytelling and reminiscing more than others. In her work differences emerged based on ethnicity with African American parents valuing narrative talk and elaborate storytelling more than Caucasian parents. In the current study, we could not tease apart SES and ethnicity, yet Heath's work suggests that the degree to which a parent engages in narrative talk might represent more of a general communicative or interactive style that may not relate to SES in the way that quantity and diversity of talk do. In the current study, high- and low-SES parents do not differ in the amount of narrative utterances they produce and this talk about the nonpresent relates to positive language outcomes for preschoolers.

Parents' use of explanations was also marginally related to later vocabulary skill (with narrative utterances and quantity of talk controlled). Explanations are challenging for children to understand, as they require making logical connections between objects, events, concepts, or conclusions (Beals, 2001). Nonetheless, these results indicate that in this diverse sample, three-and-a-half-year-olds are not too young to understand explanations about how things work in the world, or conversations 
about previous or future events, and that indeed this type of challenging, decontextualized talk might be just what they need to help facilitate vocabulary acquisition further at this age. As with narratives it could be that the child is playing a role here. For example, some children may elicit more explanations from their parents by asking more "why" questions or by just being more interested in how things operate in the world. Thus, it is unclear if parents produce more explanations on their own initiative or because of characteristics of their children, or both.

In conclusion, the results of this study suggest that parents can scaffold their children's vocabulary acquisition at different points in development by providing them with exposure to different types of talk. These results are consistent with an interactionist perspective toward language learning, in that differences in parent input are associated with differences in children's language abilities. These results also speak to the role of interaction in cognitive development more broadly, in that positive results are seen when parents communicate with their children at a level that challenges them yet provides support and multiple opportunities to learn (Bruner, 1983; Vygotsky, 1978). For example, asking a 42-month-old to recall something that happened in the past and relate it to the current situation is challenging yet appropriate given the child's age and language abilities, whereas demanding the same of an 18-month-old might be asking too much and not facilitate language and cognitive growth to the extent that using a lot of words and a diverse vocabulary might.

In light of the study's contributions, there are several important limitations, most notably that while some important measures of quality were examined it was impossible to include measures of all potentially important aspects of parental input. Thus, future research should investigate other measures of quality, taking into consideration the age and language ability of the children being studied. While quantity is certainly part of the story, the results presented here show that there is much to gain from looking at quality, both in terms of predicting children's language development and in terms of understanding the mechanisms through which input might affect language. Much has been made recently of the importance of quantity of parental input as an important factor affecting later language development, yet the current findings suggest that not all talk is equally influential. Rather, it would also be helpful for parents to con- centrate on the quality of their talk, incorporating a diverse and sophisticated vocabulary with toddlers and engaging their preschool children in conversations about past or future events.

\section{References}

Anderson, R. C., \& Freebody, P. (1981). Vocabulary knowledge. In J. T. Guthrie (Ed.), Reading comprehension and education (pp. 77-117). Newark, DE: International Reading Association.

Beals, D. (1997). Sources of support for learning words in conversation: Evidence from mealtimes. Journal of Child Language, 24, 673-694.

Beals, D. (2001). Eating and reading: Links between family conversations with preschoolers and later language and literacy. In D. K. Dickinson \& P. O. Tabors (Eds.), Beginning literacy with language: Young children learning at home and school (pp. 75-92). Baltimore: Brookes.

Beals, D., \& Snow, C. E. (1994). "Thunder is when the angels are upstairs bowling": Narratives and explanations at the dinner table. Journal of Narrative and Life History, 4, 331-352.

Beals, D., \& Tabors, P. (1995). Arboretum, bureaucratic, and carbohydrates: Preschoolers' exposure to rare vocabulary at home. First Language, 15, 57-76.

Braine, M. D. S. (1994). Is nativism sufficient? Journal of Child Language, 21, 9-32.

Bruner, J. S. (1983). Children's talk: Learning to use language. New York: Norton.

Chall, J., \& Dale, E. (1995). Readability revisited and the new Dale-Chall readability formula. Cambridge, MA: Brookline Books.

Cunningham, A. E., \& Stanovich, K. E. (1997). Early reading acquisition and its relation to reading experience and ability 10 years later. Developmental Psychology, 33, 934-945.

Dale, E., \& Chall, J. (1948). A formula for predicting readability. Educational Research Bulletin, 27, 11-20; 3754.

DeTemple, J. M. (2001). Parents and children reading books together. In D. K. Dickinson \& P. O. Tabors (Eds.), Beginning literacy with language: Young children learning at home and school (pp. 31-52). Baltimore: Brookes.

Duncan, G. J., Yeung, W. J., Brooks-Gunn, J., \& Smith, J. R. (1998). How much does childhood poverty affect the life chances of children? American Sociological Review, $63,406-423$.

Dunn, L. M., \& Dunn, L. M. (1997). Peabody Picture Vocabulary Test (3rd ed.). Circle Pines, MN: American Guidance Service.

Durham, R. E., Farkas, G., Hammer, C. S., Tomblin, J. B., \& Catts, H. W. (2007). Kindergarten oral language skill: A key variable in the intergenerational transmission of socioeconomic status. Research in Social Stratification and Mobility, 25, 294-305. 
Farkas, G., \& Beron, K. (2004). The detailed age trajectory of oral vocabulary knowledge: Differences by class and race. Social Science Research, 33, 464-497.

Fenson, L., Dale, P., Reznick, J. S., Bates, E., Thal, D., \& Pethick, S. (1994). Variability in early communicative development. Monographs for the Society for Research in Child Development 59(Serial No. 242).

Fivush, R., \& Fromhoff, F. A. (1988). Style and structure in mother-child conversations about the past. Discourse Processes, 11, 337-355.

Furr, R. M. (2008). A contrast analysis approach to change. Educational Research and Evaluation: An International Journal on Theory and Practice, 14, 335-362.

Haden, C., Haine, R., \& Fivush, R. (1997). Developing narrative structure in parent-child reminiscing across the preschool years. Developmental Psychology, 33, 295307.

Hart, B., \& Risley, T. (1995). Meaningful differences in the everyday experience of young American children. Baltimore: Brookes.

Heath, S. B. (1983). Ways with words: Language, life and work in communities and classrooms. Cambridge, UK: Cambridge University Press.

Hoff, E. (2003a). The specificity of environmental influence: Socioeconomic status affects early vocabulary development via maternal speech. Child Development, $74,1368-1378$.

Hoff, E. (2003b). Causes and consequences of SES-related differences in parent-to-child speech. In M. H. Bornstein \& R. H. Bradley (Eds.), Socioeconomic status, parenting, and child development (pp. 147-160). Mahwah, NJ: Erlbaum.

Hoff, E. (2006). How social contexts support and shape language development. Developmental Review, 26, 55-88.

Hoff, E., \& Naigles, L. (2002). How children use input to acquire a lexicon. Child Development, 73, 418-433.

Huttenlocher, J., Haight, W., Bryk, A., Seltzer, M., \& Lyons, T. (1991). Early vocabulary growth: Relation to language input and gender. Developmental Psychology, $27,236-248$.

Huttenlocher, J., Waterfall, H., Vasilyeva, M., Vevea, J., \& Hedges, L. V. (2010). Sources of variability in children's language growth. Cognitive Psychology, 61, 343-365.

Katz, J. R. (2001). Playing at home: The talk of pretend play. In D. K. Dickinson \& P. O. Tabors (Eds.), Beginning literacy with language: Young children learning at home and school (pp. 53-73). Baltimore: Brookes.

McCabe, A., \& Peterson, C. (1991). Getting the story: A longitudinal study of parental styles in eliciting oral personal narratives and developing narrative skill. In
A. McCabe \& C. Peterson (Eds.), Developing narrative structure (pp. 217-253). Hillsdale, NJ: Erlbaum.

Newport, E. L., Gleitman, H., \& Gleitman, L. (1977). Mother, I'd rather do it myself: Some effects and noneffects of maternal speech style. In C. E. Snow \& C. A. Ferguson (Eds.), Talking to children: Language input and acquisition (pp. 109-150). Cambridge, UK: Cambridge University Press.

Peterson, C., \& McCabe, A. (1994). A Social interactionist account of developing decontextualized narrative skill. Developmental Psychology, 30, 937-948.

Rosenthal, R., Rosnow, R. L., \& Rubin, D. B. (2000). Contrasts and effect sizes in behavioral research: A correlational approach. Cambridge, UK: Cambridge University Press.

Rowe, M. L., \& Goldin-Meadow, S. (2009). Differences in early gesture explain SES disparities in child vocabulary size at school entry. Science, 323, 951-953.

Snow, C. E. (1972). Mothers' speech to children learning language. Child Development, 43, 549-565.

Snow, C. E. (1990). The development of definitional skill. Journal of Child Language, 17, 697-710.

Snow, C. E. (1994). Beginning from baby talk: Twenty years of research on input and interaction. In C. Gallaway \& B. Richards (Eds.), Input and interaction in language acquisition (pp. 3-12). Cambridge, UK: Cambridge University Press.

Snow, C. E., Burns, S., \& Griffin, P. (Eds.). (1998). Preventing reading difficulties in young children. Washington, DC: National Academy Press.

Snow, C. E., \& Dickinson, D. K. (1990). Social sources of narrative skills at home and at school. First Language, 10, 87-103.

Snow, C. E., Tabors, P. O., \& Dickinson, D. K. (2001). Language development in the preschool years. In D. K. Dickinson \& P. O. Tabors (Eds.), Beginning literacy with language: Young children learning at home and school (pp. 1-25). Baltimore: Brookes.

Stromswold, K. (2001). The heritability of language: A review and metaanalysis of twin, adoption, and linkage studies. Language, 77, 647-723.

Tomasello, M., \& Farrar, M. J. (1986). Joint attention and early language. Child Development, 57, 1454-1463.

Vygotsky, L. S. (1978). Mind in society: The development of higher psychological processes. Cambridge, MA: Harvard University Press.

Weizman, Z. O., \& Snow, C. E. (2001). Lexical input as related to children's vocabulary acquisition: Effects of sophisticated exposure and support for meaning. Developmental Psychology, 37, 265-279. 
This document is a scanned copy of a printed document. No warranty is given about the accuracy of the copy. Users should refer to the original published version of the material. 